These experiments indicate that vitamin $B_{12}$ affected the conversion of formate to choline, and therefore presumably to methyl groups, more than any other reaction, suggesting a function in an oxidation-reduction system related directly or indirectly to the metabolism of formate.

National Institute for Medical Research, Mill Hill, London (Great Britain)

H. R. V. ARNSTEIN

1 H. R. V. Arnstein and A. Neuberger, Biochem. J., 55 (1953) 259.

2 W. G. Verly and W. J. Cathey, J. Biol. Chem., 2 I 3 (I955) 621 ,

3 J. A. Stekol, S. Weiss and K. W. Werss, Arch. Biochem. Biophys., 36 (1952) 5.

Received June $7^{\text {th }}, 195^{8}$

\title{
Enzymic synthesis of $\mathbf{N}$-acetyl-D-mannosamine*
}

As reported earlier ${ }^{1}$, an enzyme purified from Clostridium perfringens ( $\mathrm{N}$-acetylneuraminic acid aldolase; NaNaldolase) catalyzes the following reversible reaction: pyruvate $+\mathrm{N}-\mathrm{acetyl}-\mathbf{D}-$ mannosamine (N-AcMm) $\nleftarrow \mathrm{N}$-acetylneuraminic acid (sialic acid). The recognition of $\mathrm{N}$-AcMm as a naturally occurring sugar leads to the question of the mechanism of biosynthesis of this compound. As indicated below, N-AcMm is formed from uridine diphosphate acetylglucosamine (UDPAG) by extracts obtained from rat liver.

A recent report ${ }^{2}$ indicated that UDPAG is converted to $\mathrm{N}$-acetylgalactosamine ( $\mathrm{N}$-AcGalm) by rat-liver extracts. In the present studies, attempts to repeat these experiments under the same conditions yielded $\mathrm{N}$-AcMm, but no detectable $\mathrm{N}$-AcGalm. Incubation mixtures were prepared as described ${ }^{2}$ using commercial UDPAG ${ }^{\star *}$; these were deproteinized with $\mathrm{Ba}(\mathrm{OH})_{2}$ and $\mathrm{ZnSO}_{4}$, and deionized with mixed-bed, ion-exchange resin. The presence of $\mathrm{N}$-AcMm in the solution was demonstrated as follows: (I) Paper chromatography on borated paper ${ }^{1,3}$ yielded a single $\mathrm{N}$-acylhexosamine spot which migrated at 0.4 times the rate obtained with $\mathrm{N}$-acetyl-D-glucosamine (N-AcGm). This value for RN.AcGm corresponds to that obtained with either N-AcMm or NAcGalm since these sugars do not separate under these conditions. (2) The addition of pyruvate and NaNaldolase to the unknown $\mathrm{N}$-acylhexosamine yielded $\mathrm{N}$-acetylneuraminic acid to the same extent as that obtained with an equivalent amount of N-AcMm. Neither N-AcGm nor N-AcGalm is active in the NaNaldolase system ${ }^{1}$. (3) Acid hydrolysis of the unknown $\mathrm{N}$-acylhexosamine gave a hexosamine which upon treatment with ninhydrin at $\mathrm{pH} 5.0^{4}$ yielded arabinose $\mathrm{e}^{5}$. Lyxose was not detected. Both glucosamine and mannosamine yield arabinose under these conditions, whereas galactosamine yields lyxose. (4) Chromatography of the unknown hexosamine on ion-exchange resin ${ }^{1,6}$ resulted in a single hexosamine peak which corresponded in position to that obtained with D-mannosamine, but differed from that obtained with D-galactosamine.

There was no detectable conversion of $\mathrm{N}-\mathrm{AcGm}$ to $\mathrm{N}$-AcMm by the rat-liver extracts.

For isolation and more complete characterization of the hexosamine formed from UDPAG, the following large-scale incubation mixture was prepared: crude rat-liver extract $(22 \mathrm{ml}), 400$ $\mu$ moles UDPAG, I.75 mmoles $\mathrm{MgSO}_{4}, \mathrm{I} .75$ mmoles cysteine, 5 mmoles Tris. $-\mathrm{HCl}$ buffer (pH 7.5), total volume $42 \mathrm{ml}$. After $2 \mathrm{~h}$ at $37^{\circ}, 228 \mu$ moles $\mathrm{N}$-acetylhexosamine were formed as determined by a modified Morgan-Elson reaction with synthetic $\mathrm{N}$-AcMm as standard. Following the addition of $0.20 M \mathrm{ZnSO}_{4}$ and $0.20 M \mathrm{Ba}(\mathrm{OH})_{2}$ (120 ml each), filtration, deionization of the mixture with mixed-bed resin, and dialysis, the dialysate was concentrated, in vacuo. The concentrate was hydrolyzed with $\mathrm{HCl}$, the resulting hexosamine isolated by ion-exchange chromatography ${ }^{1,6}$, and crystallized as the hydrochloride from methanol (first crop, $20 \mathrm{mg}$ ). After recrystallization, the material exhibited the following analyses:

$$
\begin{array}{r}
\text { Calcd. for } \mathrm{C}_{6} \mathrm{H}_{14} \mathrm{O}_{5} \mathrm{NCl}: \mathrm{C}, 33.42 ; \mathrm{H}, 6.54 ; \mathrm{N}, 6.50 ; \mathrm{Cl}, 16.44 \\
\text { Found: } \mathrm{C}, 33,24 ; \mathrm{H}, 6.68 ; \mathrm{N}, 6.47 ; \mathrm{Cl}, 16.3^{6} .
\end{array}
$$

* The Rackham Arthritis Research Unit is supported by a grant from the Horace H. Rackham School of Graduate Studies. The expenses of this study were defrayed in part by grants from the Michigan Chapter, Arthritis and Rheumatism Foundation, and Grant A-512 from the United States Public Health Service, through the National Institute of Arthritis and Metabolic Diseases.

* The UDPAG (Sigma Chemical Co.) is reported to be $95^{-100 \%}$ pure, and is obtained from yeast. Acid hydrolysis followed by paper chromatography yielded N-AcGm and no detectable $\mathrm{N}$-AcGalm or N-AcMm. 
The crystals exhibited $[a]_{\mathrm{D}}^{25}=-3.9^{\circ}(c$, I.2\% in water $)$. Finally, the X-ray powder diffraction pattern of the material was identical to that obtained with synthetic $D$-mannosamine hydrochloride, but differed from the patterns obtained with D-glucosamine hydrochloride, and $\mathrm{D}-$ galactosamine hydrochloride (Fig. I).

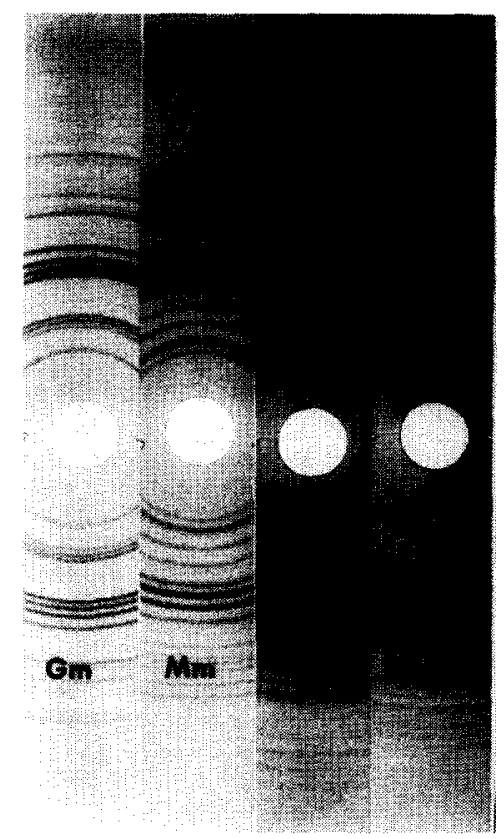

Fig. I. X-ray powder diffraction patterns of D-glucosamine hydrochloride (Gm), D-mannosamine hydrochloride $(\mathrm{Mm})$, the hexosamine hydrochloride isolated from the reaction mixture (X), and D-galactosamine hydrochloride (Galm).

These results indicate that crude rat-liver extracts are capable of converting UDPAG, but not $\mathrm{N}-\mathrm{AcGm}$, to $\mathrm{N}-\mathrm{AcMm}$. The mechanism of this enzymic reaction is under investigation.

Rackham Arthritis Research Unit and Department of Biological Chemistry,

D. G. COMB ${ }^{\text {* }}$ University of Michigan, Ann Arbor, Mich. (U.S.A.)

S. ROSEMAN

1 D. G. Comb and S. Roseman, J. Am. Chem. Soc., 80 (1958) 49\%.

2 C. E. Cardini and L. F. Leloir, J. Biol. Chem., 225 (I957) 317.

3 E. Cabib, L. F. Leloir and C. E. Cardini, J. Biol. Chem., 203 (1953) I055.

4 H. G. Pontis, J. Biol. Chem., 2 I6 (I955) 195.

5 P. J. Stoffyn and R. W. Jeani.oz, Arch. Biochem., 52 (1954) 373

6 S. Gardell, Acta Chem. Scand., 7 (1953) 207.

7 J. I. Reissig, J. L. Strominger and L. F. Leloir, J. Biol. Chem., 217 (I955) 959.

Received May 13th, $195^{8}$

\footnotetext{
* Postdoctoral fellow, American Cancer Society.
} 